\title{
Launching WordPress- Blogs and Domains
}

\author{
Nishu Sethi, Neha Bhateja, Shivangi Kaushal, Juhi Singh
}

\begin{abstract}
In today's world, the emphasis is on to move toward the digital driven economy, businesses, and human life. This huge movement towards digitization has resulted in generation of humongous amount of digital content. Managing this digital content is a challenge in it itself. A content management system provides way to handle this data efficiently. CMS are software applications that provide us the capability for easy management and maintainability of this digital content. The number of content management systems have been developed and successfully productionized such as Word press, Joomla, Cascade Server, Wix etc. the paper provides an overview of capabilities of WordPress CMS and various functionalities it offers for digital content management.
\end{abstract}

KEYWORDS- Blogs, Domain, SEO, Website, CMS.

\section{INTRODUCTION}

The content management system (CMS) is a software application specifically designed to create as well as to manage digital content. It enables a user or set of users to collaborate and produce easy manageable digital content. CMS [8] are generally a user-friendly application which does not require knowledge of any specific programming language or scripting language for operation. There are number of applications of using CMs which range from creating a website for business entity to writing blogs [10] for personal as well professional thoughts sharing.
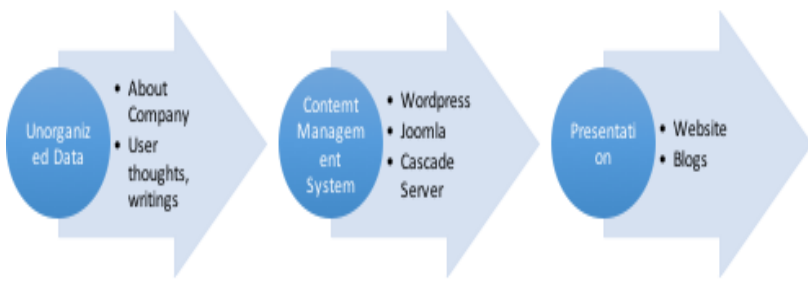

Fig 1: Process of managing digital content

Manuscript received May 19, 2020

Nishu Sethi, Department of Computer Science, Amity University, Gurgaon, Haryana, India (email: sethinishu@gmail.com)

Neha Bhateja, Department of Computer Science, Amity University, Gurgaon, Haryana, India

Shivangi Kaushal, Department of Computer Science, Amity University, Gurgaon, Haryana, India.

Juhi Singh, Department of Computer Science, Amity University, Gurgaon, Haryana, India.

\section{RELATED WORK}

Leone S. et. al [11] proposed the plugin to managing ER models. There are a variety of tools made for systematic flow in today's world of web engineering. Furthermore, the quality of the domain is vital part which was proposed by Ziemba P. et. al [12] in which the authors used knowledge management as a tool. In support of WordPress, many blogs are written on daily basis as it is a tool for content management. A blog from Aspire [2] states the different benefits of using it, of which most important is multiple users, plug-ins and a lot more. There is also a competition in which Content Management System [14] to be used based on some parameters such as page size, page load time, etc. Furthermore, there is another proposed paper related to the comparison of CMS tools [15] such as popularity, budget, social bookmarking. Khan Z.M. [6] proposed a paper which says WordPress an important tool in management contents relating the advantages and disadvantages of the application. The motive is to design the WordPress [17] to provide a good platform for blogging, but over the year it become popular by providing the good features such as customization, themes and more over it is user friendly and more than $45 \mathrm{~K}$ plug-in, templates etc, Besides WordPress [16] many popular content management systems are available on a single click on Google, such as Joomla, Drupal, Plone, Xoops, etc. In short WordPress successfully completed its journey from the CMS to open source website creation tools. The cost of the website creation is one of the key factor that also affect the popularity and market growth as the market coverage, as shown in fig 2[18].

\begin{tabular}{ll}
\hline CMS & Market coverage \\
WordPress & $62.6 \%$ \\
Joomla! & $4.4 \%$ \\
Shopify & $3.6 \%$ \\
Drupal & $2.9 \%$ \\
Squarespace & $2.6 \%$ \\
Wix & $2.3 \%$ \\
Bitrix & $1.6 \%$ \\
Blogger & $1.6 \%$ \\
Magento & $1.4 \%$ \\
PrestaShop & $1.0 \%$ \\
OpenCart & $0.9 \%$ \\
TYPO3 & $0.7 \%$ \\
Weebly & $0.6 \%$ \\
Adobe Dreamweaver & $0.5 \%$ \\
FrontPage & $0.4 \%$ \\
\hline
\end{tabular}

Fig 2: Market coverage of CMS [18] 
One of the key factors to increase the popularity index of core Wordpress is security since it is being audited regularly [19], open source tools are vulnerable to attack, WordPress provide easiness and it is cost effective as well. But when it comes to the online platform, as WordPress offers the high customization and turnoff facility to its user, these features makes it more secure than other existing CMS tools.

\section{WORDPRESS}

Word Press is an open source system [7] which is used to manage the content and to create a website, blog, or an application. It is one of the leading content management tools [6] which are freely available to the user to create the websites or blogs. The layered Architecture [6] of Word press consists of Framework Plugins, Web Framework, language, Server, database, and an Operating System to work with.

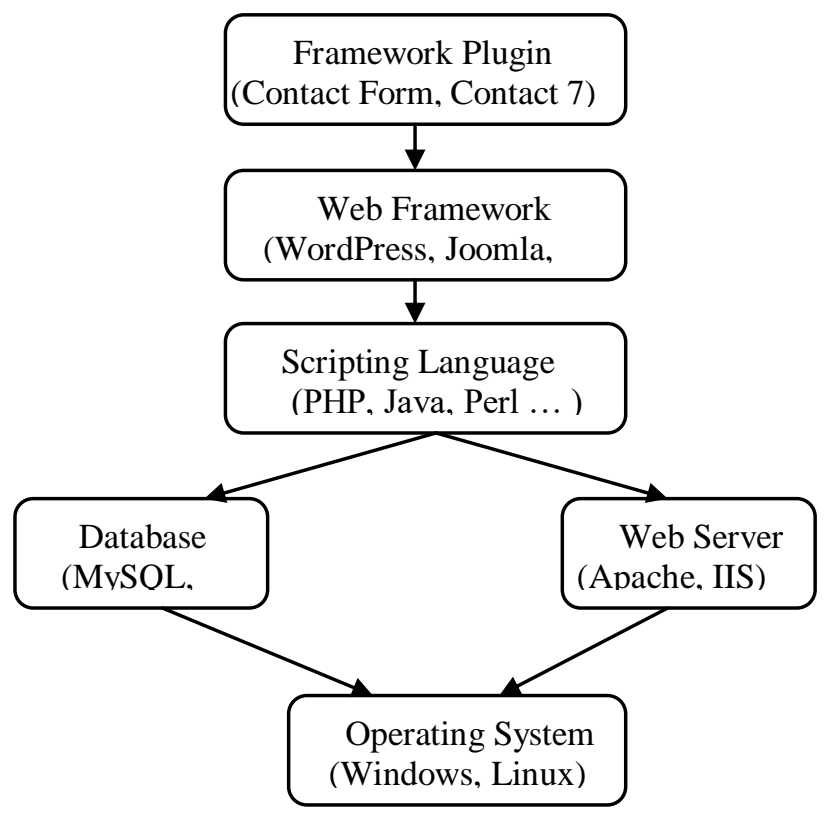

Fig 3: Layered architecture of WordPress [6]

\section{NEED OF WORDPRESS [2]}

- Most of the websites are developed in WordPress.

- This is not just used for Blog Writing and can be used for Content Management System of Various Companies.

- Word Press is avaricious

- Word Press is Convenient

- Word Press can be contorted easily

\section{PROCESS TO CREATE A WORDPRESS}

The following Fig 4. represents the step by step process of creating a Word Press [1].

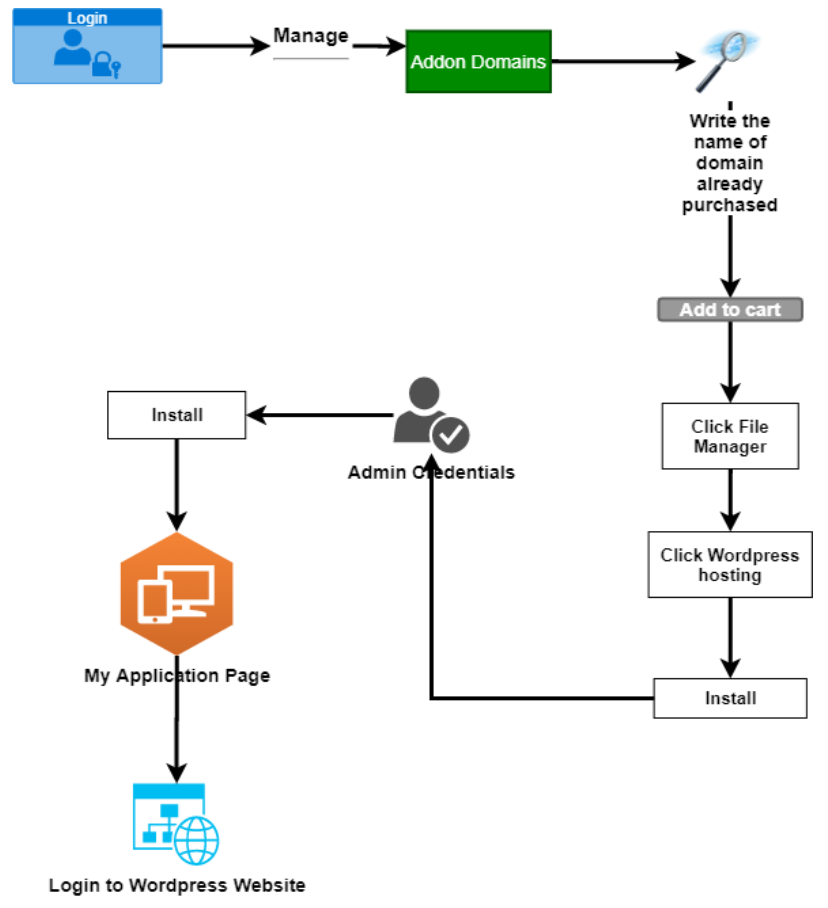

Fig 4: Process to Create a Word Press Website

\section{DOMAIN}

These are used for identifying the IP addresses, and are used in Uniform Resource Locator for locating a website. Example: .com, .in, .edu, .gov. etc.

\section{A. Selecting domain [12]}

- Make it effortless [11] to write: The domain chosen should be easily written and read.

- Define precisely: The domain should be accurate and define the exactness of a specific thing.

- Use keywords [13]: Since Keywords are very catchy; using keywords for the domain makes the task easier.

- Define your area: Certain policies are to be considered before choosing or creating a domain name. One must be very precise in selecting the area of the domain.

- Avoid Numbers and hyphens: Domain name does not include hyphens and numbers.

- Reexamine it (check for copyright infringements or trademarks): Once you have chosen the domain name, check for its existence and copyrights. If it already exists, you need to change the domain name.

- Choose a domain name extension: The extension specifying your organization should be chosen appropriately.

- Protect and build your brand: Once the domain is ready, now you can build your own brand.

- Act fast: Since the domain is created, publish it by fulfilling the formalities and can be viewed by the users.

\section{ACCESSING WORD PRESS}

- Select the desired template [4] from the available pool and launch the Word Press.

- Post and Page definitions.

- Media upload on Word press

- Defining Blogging and Website [5] 


\section{BASIC CONTRIVE ON WORDPRESS}

1) Start with appearance option

2) Themes, Menu, Customize, Theme Option

3) Popular WORDPRESS Plugins Page Builder [3]

4) Revolution Slider (Paid)

5) Yoast SEO

6) Yoast Google Analytics

7) Contact Form 7

\section{COMPOSING A BLOG POST [9]}

1. Understanding the audience: Every single person today is using social media today, out of all we must choose those who have common interest as ours.

2. Start with the subject and working title

3. Write an introduction (and make it fascinating)

4. Organize the content [10] (sections, short paragraph, lists, tips etc.)

5. Edit the post and fixing the formatting

6. Reform for on-page SEO

\section{CONCLUSION AND FUTURE SCOPE}

To conclude, the paper presents various aspects of WordPress CMS including the functionalities provided and the step by step process to access those functionalities. In addition to it WordPress provides an open source, customizable and efficient tool to manage the digital content. WordPress provides several free themes as well as some paid themes which makes it a perfect option for anyone who wants to create websites, write blogs etc.

The limitation with the use of word press is that the plugins cannot be uploaded in these and paid posts can't be written in these. If we buy the themes available, then the content becomes more easily available.

\section{REFERENCES}

[1] E.Staff, "7 Best Analytics solutions for WordPress", Available:http://www.wpbeginner.com/showcase/7-be stanalytics-solutions-for-wordpress-users/.

[2] W. Company, "10 benefits of using WordPress to power your company's Website," Available: http://aspireid.com/webdesign/10-benefits-of-using-w ordpress-to-power-your-businesswebsite/.

[3] Tom Ewar, "14 surprising statistics about WordPress", Available

:https://managewp.com/14-surprising-statisticsaboutwordpress-usage

[4] H. Moreno, "WordPress fans beware: Main disadvantages of using WordPress",Available: http://www.onextrapixel.com/2014/

10/01/wordpress-fans-beware-main-disadvantages-ofusingwordpress/

[5] B. Ünver, "How to effectively validate a WordPress Website",Available: https://code.tutsplus.com/tutorials/how-toeffectively-v alidate-a-wordpress-website--cms-20529.

[6] Z. M. Khan, K. Rasheed, and M. Imran, "WordPress: A Versatile Tool for Managing Contents," International Journal of Scientific \& Engineering Research, vol. 8, no. 2, pp. 786-789, Feb. 2017.
[7] Wordpress, www.wordpress.org

[8] Content Management System https://www.wpbeginner.com/glossary/content-manag ement-system-cms/

[9] J.R. Baker and S.M. Moore, 2008. "Blogging as a social tool: A psychosocial examination of the effects of blogging," Cyberpsychology \& Behavior, volume 11 , number 6, pp. 747-749.

[10] Shema, Hadas \& Bar-Ilan, Judit \& Thelwall, Mike. (2012). Research Blogs and the Discussion of Scholarly Information. PloS one. 7. e35869. 10.1371/journal.pone.0035869.

[11]Leone S., de Spindler A., Norrie M.C. (2012) A Meta-plugin for Bespoke Data Management in WordPress. In: Wang X.S., Cruz I., Delis A., Huang G. (eds) Web Information Systems Engineering - WISE 2012. WISE 2012. Lecture Notes in Computer Science, vol 7651. Springer, Berlin, Heidelberg.

[12]Ziemba P., Jankowski J., Wątróbski J., Becker J. (2015) Knowledge Management in Website Quality Evaluation Domain. In: Núñez M., Nguyen N., Camacho D., Trawiński B. (eds) Computational Collective Intelligence. Lecture Notes in Computer Science, vol 9330. Springer, Cham.

[13] https://patents.google.com/patent/US7281042B2/en.

[14] Patel S.K., Rathod V.R., and Parikh S. (2012) Joomla, Drupal and WordPress - a statistical comparison of open source CMS. In: 3rd International Conference on Trendz in Information Sciences \& Computing (TISC2011), IEEE Explore

[15] Patel S.K., Rathod V.R., and Prajapati B.J. (2011) Performance Analysis of Content Management Systems- Joomla, Drupal and WordPress. In: International Journal of Computer Applications, Vol 21, 4, pp. 39-43.

[16] http://citeseerx.ist.psu.edu/viewdoc/download?doi=10 1.1.206.3027\&rep=rep $1 \&$ type $=$ pdf

[17] https://www.sktthemes.org/fyi/cms-comparison - wordpress-joomla-drupal/

[18] https://www.ionos.com/digitalguide/hosting/cms / cms-comparison-a-review-of-the-best-platforms/

[19] https://www.wpbeginner.com/wordpress-security/ 